\title{
Cerebral blood flow, arteriovenous oxygen difference, and outcome in head injured patients
}

\author{
C S Robertson, C F Contant, Z L Gokaslan, R K Narayan, R G Grossman
}

\begin{abstract}
Cerebral blood flow (CBF) and other physiological variables were measured repeatedly for up to 10 days after severe head injury in 102 patients, and CBF levels were related to outcome. Twenty five of the patients had a reduced CBF [mean (SD) $0.29(0.05) \mathrm{ml} / \mathrm{g} / \mathrm{min}$ ]; $47 \mathrm{had}$ a normal CBF, $(0.41(0 \cdot 10) \mathrm{ml} / \mathrm{g} / \mathrm{min})$; and 30 had a raised CBF (0.62 (0.14) $\mathrm{m} 1 / \mathrm{g} / \mathrm{min})$. Cerebral arteriovenous oxygen difierences were inversely related to CBF and averaged $2.1(0.7) \mu \mathrm{mol} / \mathrm{ml}$ in the group with reduced CBF, $1.9(0.5) \mu \mathrm{mol} / \mathrm{ml}$ in the group with normal CBF, and 1.6 $(0.4) \mu \mathrm{mol} / \mathrm{ml}$ in the group with raised CBF. Patients with a reduced CBF had a poorer outcome than patients with a normal or raised CBF. Mortality was highest in patients with a reduced CBF, and was $32 \%$ at three months after injury, whereas only $21 \%$ of the patients with a normal $\mathrm{CBF}$ and $20 \%$ of the patients with a raised CBF died. There were no differences in the type of injury, initial score on the Glasgow Coma Scale, mean intracranial pressure (ICP), highest ICP, or the amount of medical treatment required to keep the ICP $<20 \mathrm{~mm} \mathrm{Hg}$ in each group. Systemic factors did not significantly contribute to the differences in CBF among the three groups. A logistic regression model of the effect of CBF on neurological outcome was developed. When adjusted for variables which were found to be significant confounders, including age, initial Glasgow Coma Score, haemoglobin concentration, cerebral perfusion pressure and cerebral metabolic rate of oxygen, a reduced CBF remained significantly associated with an unfavourable neurological outcome.
\end{abstract}

Many factors contribute to the long term neurological disability incurred by a patient who has sustained a severe head injury. The pathology produced by the injury, the patient's neurological status, the severity of intracranial hypertension, and the age of the patient have been identified as determinants of outcome after head injury, but despite numerous studies of cerebral blood flow (CBF) in head injured patients the relation of CBF to outcome is poorly understood..$^{1-13}$

Table 1 summarises the findings of studies that have examined the association of $C B F$ and outcome after head injury. Some of these studies have reported that a very low CBF was associated with a poor outcome. Overgaard et al reported regional CBF values of $<0.20 \mathrm{ml} /$ $\mathrm{g} / \mathrm{min}$ in $61 \%$ of patients with outcomes of death/severely disabled/vegetative. Only $10 \%$ of patients with a good outcome had regional CBF values at this low level. ${ }^{9}$ Overgaard and Tweed reported that patients who died or remained vegetative commonly had very low CBF in arterial boundary zones and had lower global CBF values than the patients who recovered. ${ }^{10}$ Other studies have correlated a moderately reduced $\mathrm{CBF}$, particularly in the first 24 hours after injury, with a poor outcome. ${ }^{12}$

Raised CBF levels have also been related to a poor neurological outcome. Fieschi et al reported that an initially low CBF returned to normal in patients who recovered but increased to raised levels in patients who died of their cerebral injury. ${ }^{3}$ Overgaard and Tweed reported a good outcome in only one of 12 patients in their series with raised CBF. ${ }^{10}$

Several points must be considered when analysing the relation between $\mathrm{CBF}$ and neurological outcome in head injured patients. Studies suggest that CBF may evolve over time after a severe head injury. ${ }^{37112}$ A single measurement or relatively infrequent measurements might not be representative of the patient's acute recovery period. Studies suggest that CBF is most likely to be low in the first 24 hours after the injury. ${ }^{9}$ Measurements of CBF obtained after 24 hours might underestimate the incidence of hypoperfusion. The optimal CBF for a patient with a severe head injury is not known, as comparisons must be made to values obtained in normal adults. Normal values, however, are obtained at a normal $\mathrm{PCO}_{2}$ while most head injured patients usually have lower $\mathrm{PCO}_{2}$ values. Since most head injured patients retain $\mathrm{CO}_{2}$ reactivity, some adjustment for $\mathrm{PCO}_{2}$ must be made to compare the patient's values with normal values. Finally, the effects of other factors known to alter outcome after severe head injury must be accounted for.

We performed serial CBF measurements up to 10 days after severe head injury in 102 patients and examined the relation between CBF, demographic characteristics, systemic factors, and outcome using multivariate analysis.

\section{Methods}

Patient characteristics and management

A total of 102 adults who had sustained severe head injury were admitted to the neurosurgical intensive care unit at Ben Taub General 
Table 1 Relation of CBF and neurological outcome reported in selected studies

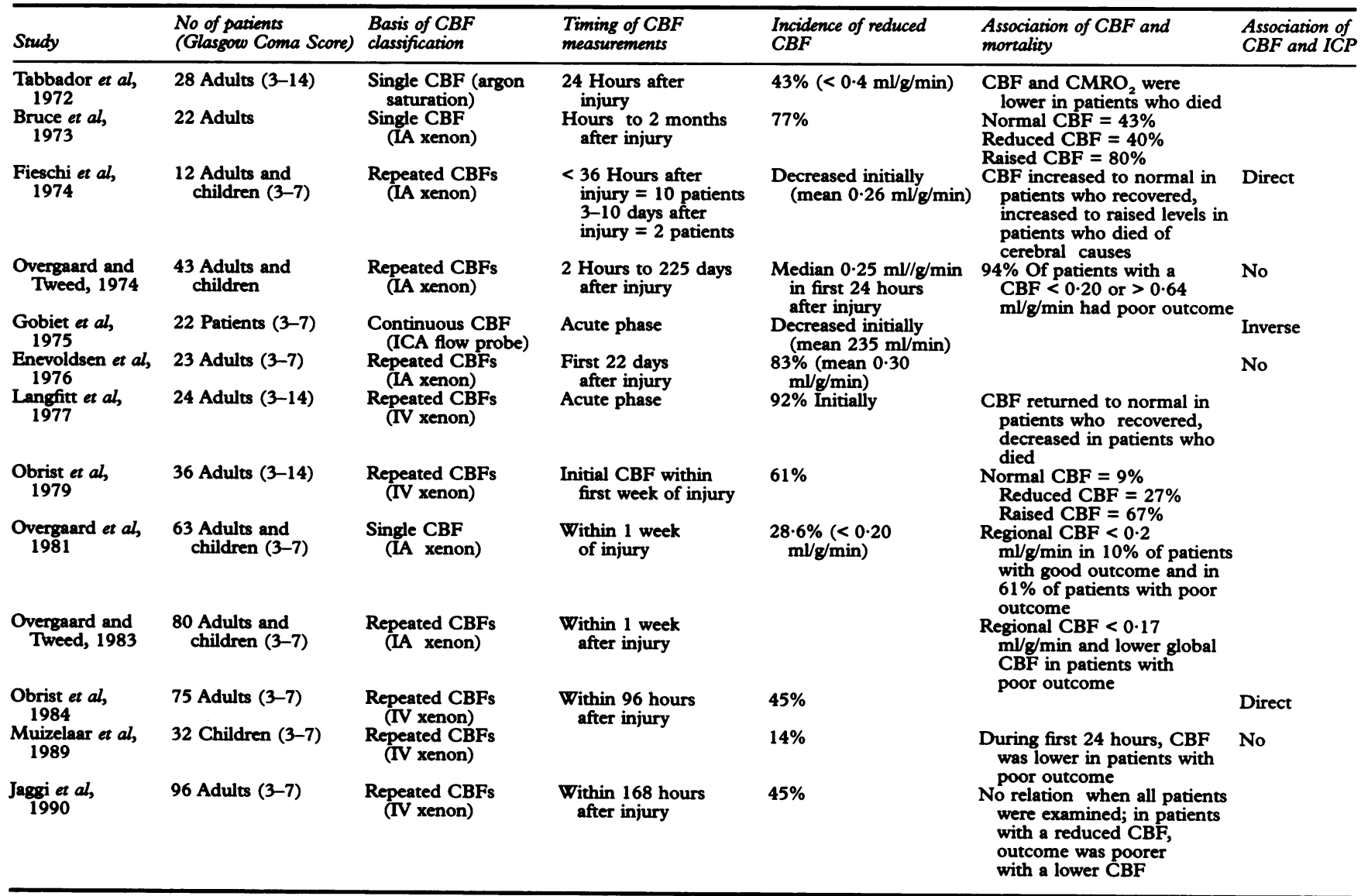

$\mathrm{CBF}=$ cerebral blood flow; $\mathrm{CMRO}_{2}=$ cerebral metabolic rate of oxygen; IA = intraarterial; IV = intravenous; ICA = internal carotid artery.

Hospital between 1 May 1983 and 30 April 1989 and had repeated measurements of CBF for up to 10 days after injury.

Eighty per cent of the patients were male (mean (SD) age 34 (11) years). Ninety per cent of the patients had closed head injuries and $10 \%$ had gunshot wounds of the brain. Ninety four per cent of the patients were in coma on admission to hospital. The initial Glasgow Coma Score (GCS) was $3-5$ in $21 \%$ of the patients and $6-8$ in $73 \%$. In $6 \%$ of the patients the initial GCS was $\geq 9$, but these patients later deteriorated to coma. Pupillary reactivity was normal in $83 \%$ of patients, absent in one pupil on $13 \%$, and absent in both pupils in $4 \%$.

Outcome was determined at three months after injury by examiners who were unaware of the data on CBF and other physiological variables. The mortality was $24 \%$. Thirty nine per cent of the patients achieved a favourable recovery, defined as a Glasgow outcome score of good recovery $(9 \%)$ or moderate disability $(30 \%)$. Sixty one per cent had an unfavourable recovery, defined as a Glasgow outcome score of severe disability, vegetative, or dead.

All patients were managed with a protocol that emphasised prompt evacuation of intracranial haematomas and prevention of secondary injury to the brain. Patients were intubated and ventilated to maintain arterial $\mathbf{P O}_{2}$ $>100 \mathrm{~mm} \mathrm{Hg}$ and a $\mathrm{PCO}_{2}$ of approximately $35 \mathrm{~mm} \mathrm{Hg}$. Medication included morphine for sedation, pancuronium, phenytoin, and anti- biotics. Steroids were not routinely administered.

Intracranial pressure (ICP) was monitored, usually by ventriculostomy, and pressures $>20 \mathrm{~mm} \mathrm{Hg}$ were treated. Intracranial hypertension was treated by drainage of cerebrospinal fluid, hyperventilation $\left(\mathrm{PCO}_{2} 25-30 \mathrm{~mm}\right.$ $\mathrm{Hg}$ ), sedation, paralysis, and mannitol. Barbiturate coma was used only if intracranial hypertension was refractory to this regimen.

\section{Physiological measurements}

Cerebral blood flow and cerebral metabolic rate of oxygen and lactate were measured daily, in some cases two to three times a day, for as long as ICP monitioring was required (range 2-10 days after injury). A total of 739 measurements of CBF (mean 7 (range 2-28) per patient) were obtained. Most of the measurements were made in the first five days after injury.

Cerebral blood flow was measured by the nitrous oxide saturation method. A catheter was inserted in the internal jugular vein and positioned so that the tip was in the jugular bulb. The catheter was placed on the side of the most severe injury or on the right side, if the injury was diffuse. A catheter was placed in the radial artery. Ten per cent $\mathrm{N}_{2} \mathrm{O}$ was introduced into the patient's inspired gases in a stepwise fashion, and timed blood samples were obtained from the arterial and jugular venous catheters during the first 16 minutes of $\mathrm{N}_{2} \mathrm{O}$ saturation. $\mathrm{CBF}$ was then calculated from 
saturation curves fitted to the $\mathrm{N}_{2} \mathrm{O}$ concentrations measured in the time blood samples. The mean value for $C B F$ in normal adults with this method is $0.5 \mathrm{ml} / \mathrm{g} / \mathrm{min} .^{14-16}$

Arterial and jugular venous blood was obtained simultaneously with measurement of CBF for determination of $\mathrm{PO}_{2}, \mathrm{PCO}_{2}, \mathrm{pH}$, oxygen saturation, haemoglobin, and lactate. $\mathrm{PO}_{2}, \mathrm{PCO}_{2}$, and $\mathrm{pH}$ were measured on a Corning 170 blood gas analyser (Ciba Corning Diagnostics, Medfield, Massachusetts). Oxygen saturation and haemoglobin were measured on an IL-282 co-oximeter (Instrumentation Laboratories, Lexington, Massachusetts). Whole blood lactate concentration was measured on a YSI-23L lactate analyser (Yellow Springs Instruments, Yellow Springs, Ohio). The normal arteriovenous difference of oxygen $\left(\mathrm{AVDO}_{2}\right)$ is $2.8 \mu \mathrm{mol} / \mathrm{ml}(6.3 \mathrm{ml} / \mathrm{dl}){ }^{16}$ The cerebral metabolic rate of oxygen $\left(\mathrm{CMRO}_{2}\right)$ and of lactate (CMRL) were calculated by multiplying the $\mathrm{CBF}$ by $\mathrm{AVDO}_{2}$ and the arteriovenous difference of lactate (AVDL), respectively. The normal $\mathrm{CMRO}_{2}$ determined by this method is $1.5 \mu \mathrm{mol} / \mathrm{g} / \mathrm{min}(3.4 \mathrm{ml} /$ $100 \mathrm{~g} / \mathrm{min}$ ), and the normal CMRL is $-0.02 \mu \mathrm{mol} / \mathrm{g} / \mathrm{min}^{16}$.

Arterial blood pressure, ICP, cerebral perfusion pressure, and rectal temperature measurements were recorded hourly. Measurements of blood haemoglobin concentration and arterial blood gases were obtained two to three times a day.

The severity of intracranial hypertension was quantitated by using the values of the average hourly ICP, the highest ICP, and the ICP treatment score, which is a measure of the intensity of treatment required to control the ICP. The treatments that were scored and the values assigned to each treatment are listed in table 2. The ICP treatment score ranged from 0 to 17. In general, an ICP treatment score of $\geq 6$ indicated the requirement of mannitol for increased intracranial pressure, while an ICP treatment score of $>10$ indicated that barbiturates were given. The score was calculated for eight hour blocks of time.

Table 2 Components of the ICP treatment score

\begin{tabular}{|c|c|c|}
\hline$I C P$ treatment & Possible scores & $\begin{array}{l}\text { Maximal score } \\
\text { for treatment }\end{array}$ \\
\hline \multicolumn{3}{|l|}{ Morphine } \\
\hline Pavilon & $\begin{array}{r}\text { None }=0 \\
\text { Any dose }=1\end{array}$ & 1 \\
\hline Pavulon & $\begin{array}{r}\text { None }=0 \\
\text { Any dose }=1\end{array}$ & 1 \\
\hline Hyperventilation & $\begin{aligned} \mathrm{PCO}_{2}>35 & =0 \\
31-35 & =1 \\
26-30 & =2 \\
<26 & =3\end{aligned}$ & 3 \\
\hline CSF draingoe & $\begin{array}{r}\text { None }=0 \\
\text { Dose }<75 \mathrm{~g}=2 \\
\geq 75 \mathrm{~g}=4\end{array}$ & 4 \\
\hline CSF drainage & $\begin{array}{r}\text { None }=0 \\
<10 \text { Times }=1 \\
\geq 10 \text { Times }=2\end{array}$ & 2 \\
\hline Barbiturate coma & $\begin{aligned} \text { None } & =0 \\
\text { Any dose } & =6\end{aligned}$ & $\begin{array}{r}6 \\
17\end{array}$ \\
\hline
\end{tabular}

\section{Classification of cerebral blood flow}

Two observers (one blinded to the outcome data) independently classified the patients as having a normal, raised, or reduced CBF. There was good agreement between the observers as measured by the kappa statistic. The following conventions were observed in assigning the patients to a CBF group.

(1) To allow comparison to normal values, each $C B F$ value was compared with the normal range of CBF at the patient's $\mathrm{PCO}_{2}$. Patients with values 2SD below or above the normal mean value were classified as having a reduced or a raised $C B F$, respectively. Patients whose CBF values were in the normal range were classified as having a normal CBF. Figure 1 shows the normal range for $\mathrm{CBF}$ over $\mathrm{PCO}_{2}$ values from 15 to 50 torr, assuming a $3 \%$ change in $\mathrm{CBF} /$ torr change in $\mathrm{PCO}_{2} .{ }^{11}$ Categorisation of a $C B F$ value as normal was not intended to imply that the CBF was physiologically appropriate for that patient but was intended to indicate only that the blood flow was in the same numerical range as in normal adults. This convention is similar to that recently adopted by other investigators ${ }^{11} 12$ and it allows comparison of the present study to previous reports.

(2) Although most patients had serial CBF values which all fell into one category, some patients had values that ranged across two or three categories. Seven patients who had a reduced CBF for at least 16 hours were included in the group with reduced CBF even though they may have had periods during which the CBF was normal or even raised. Patients who had periods of both normal and raised values were included in the group with raised CBF.

(3) Cerebral blood flow abnormalities that were transient and could be directly attributed to systemic causes, such as hypocapnia, hypoxia, or hypotension or to administration of drugs such as barbiturates were eliminated from consideration in assigning the patient to a CBF category. These episodes are described more completely below.

Examples of typical patients in the three groups are shown in figure 2. Each graph shows the normal limits for the individual CBF

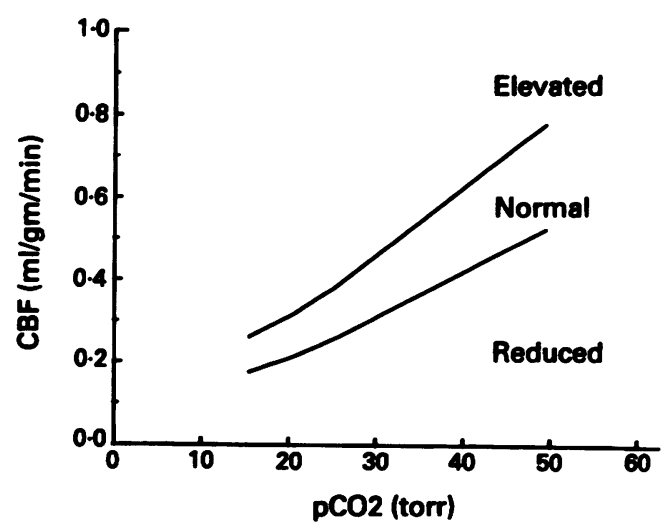
Figure 1 Normal values for $C B F$ over arterial $\mathrm{PCO}_{2}$
values ranging from 15 to 50 torr. 
Figure 2 Examples illustrating the classification of patients into three $C B F$ groups. In each graph the normal limits for the individual $C B F$

measurements are shown by the dotted lines. (a) Patient with raised $C B F$ after removal of an acute subdural haematoma. (b) Patient who maintained normal $C B F$ values during the first six days after injury. (c) Patient with reduced $C B F$ values during the first five days after injury.
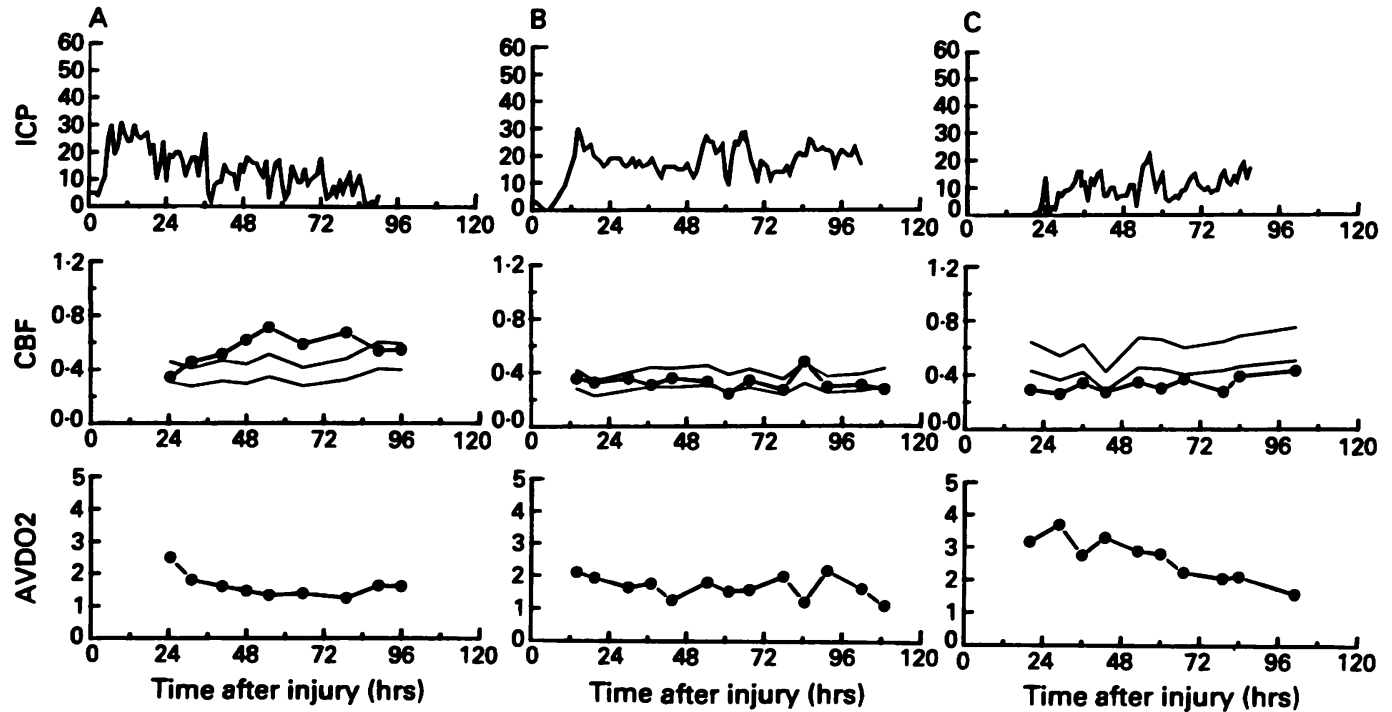

measurements. These may vary for each measurement if the patient's $\mathrm{PCO}_{2}$ values varied. Figure 2(a) shows a patient included in the group with raised CBF, who had a transient period of hyperaemia after removal of an acute subdural haematoma. Although the initial CBF values were within the normal limits, the values between hours 28 and 84 were clearly above the normal limits. By hours 86 to 96 the values began to return to normal limits. Figure 2(b) shows a patient with a gunshot wound of the head who maintained CBF values within the normal limits throughout the first six days after injury. Figure 2(c) shows a patient who had CBF values below the normal limits throughout the five day period of monitoring after evacuation of an intracerebral haematoma.

\section{Statistical analysis}

Differences in means were tested using one way analysis of variance or the $t$ test. Differences in proportions were tested with the $\chi^{2}$ statistic for contingency tables. To determine if a variable was potentially acting as a confounder, its association with both CBF and outcome was examined. Those variables that were related to either variable at the $p<0.20$ level were subsequently included as possible confounders in the logistic regression model.

Logistic regression was used to test the relation of CBF with outcome while simultaneously adjusting for multiple confounders. ${ }^{17}$ The logistic coefficients yield estimates of the $\log$ of the relative increase or decrease in probability of favourable outcome (good recovery/moderate disability) per unit change in the associated variable. The model was fitted in a forward selection manner, with CBF group, age, and Glasgow Coma Scale category (3-6 v $>6$ ) forced into the model in the first step. The final model contains only those additional variables that were significantly associated with outcome.

\section{Results}

Cerebral blood flow, $A V D O_{2}$ and $A V D L$

Cerebral blood flow was reduced in 25 patients [mean 0.29 (SD 0.05) $\mathrm{ml} / \mathrm{g} / \mathrm{min}$ ], normal in 47 $(0.41(0.10) \mathrm{ml} / \mathrm{g} / \mathrm{min})$, and raised in $30(0.62$ $(0 \cdot 14) \mathrm{ml} / \mathrm{g} / \mathrm{min})$. The intergroup differences in CBF were inversely related to differences in the $\mathrm{AVDO}_{2}$, which averaged $2 \cdot 1(0.7) \mu \mathrm{mol} / \mathrm{ml}$ in the group with reduced CBF, $1.9(0.5) \mu \mathrm{mol} /$ $\mathrm{ml}$ in the group with normal $\mathrm{CBF}$, and 1.6 $(0.4) \mu \mathrm{mol} / \mathrm{ml}$ in the group with raised CBF. The AVDL was lowest in the group with raised $\mathrm{CBF}$, averaging $-0.03(0.07) \mu \mathrm{mol} / \mathrm{ml}$, compared with $-0.07(0.12) \mu \mathrm{mol} / \mathrm{ml}$ in the group with normal CBF and $-0.06(0.12) \mu \mathrm{mol} / \mathrm{ml}$ in the group with reduced $\mathrm{CBF}$, but the differences were not significant.

Figure 3 shows the distribution of $C B F$ and $\mathrm{AVDO}_{2}$ measurements in the three groups of patients. Differences not only in CBF level but also in the ratio between $\mathrm{CBF}$ and cerebral metabolism, as reflected by the $\mathrm{AVDO}_{2}$ (that is, $\mathrm{CMRO}_{2} / \mathrm{CBF}$ ), separated the patients into

Serial cerebral blood flow measurements over time

Figures 4, 5, and 6 show the distribution of the CBF values obtained during successive eight hour periods for the groups with reduced, normal, and raised CBF. A reduced CBF was typically present on the initial measurement of CBF (16 patients, fig 4A) or developed within the first $\mathbf{4 8}$ hours after injury (seven patients). In these seven patients, the initial CBF was raised in two (fig 4B) and was normal in the remaining five (fig 4C). Two additional patients who were not comatose, and therefore not monitored on admission to the hospital, later deteriorated to coma. Initial CBF values were found to be reduced on the fifth and sixth days after injury, when they neurologically deteriorated (fig 4D). CBF remained reduced throughout the acute recovery phase in these patients. In the patients who died of intracranial hypertension the CBF fell to very low values as the ICP became uncontrollable. In only three patients did the CBF recover to normal values during the period of monitoring.

A normal CBF (fig 5) was present throughout the period of monitoring in 47 patients. A distinct groups. 
Figure 3 Distribution of individual $C B F$ and $\mathrm{AVDO}_{2}$ measurements in three $C B F$ groups. (a)

$C B F$ measurements. (b) $A V D O_{2}$ measurements.

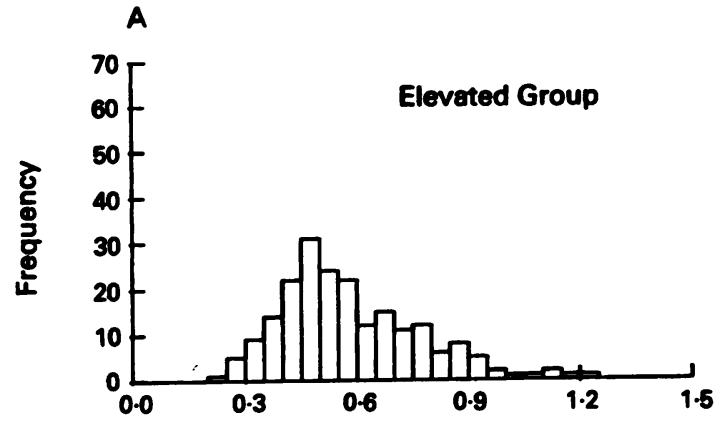

B
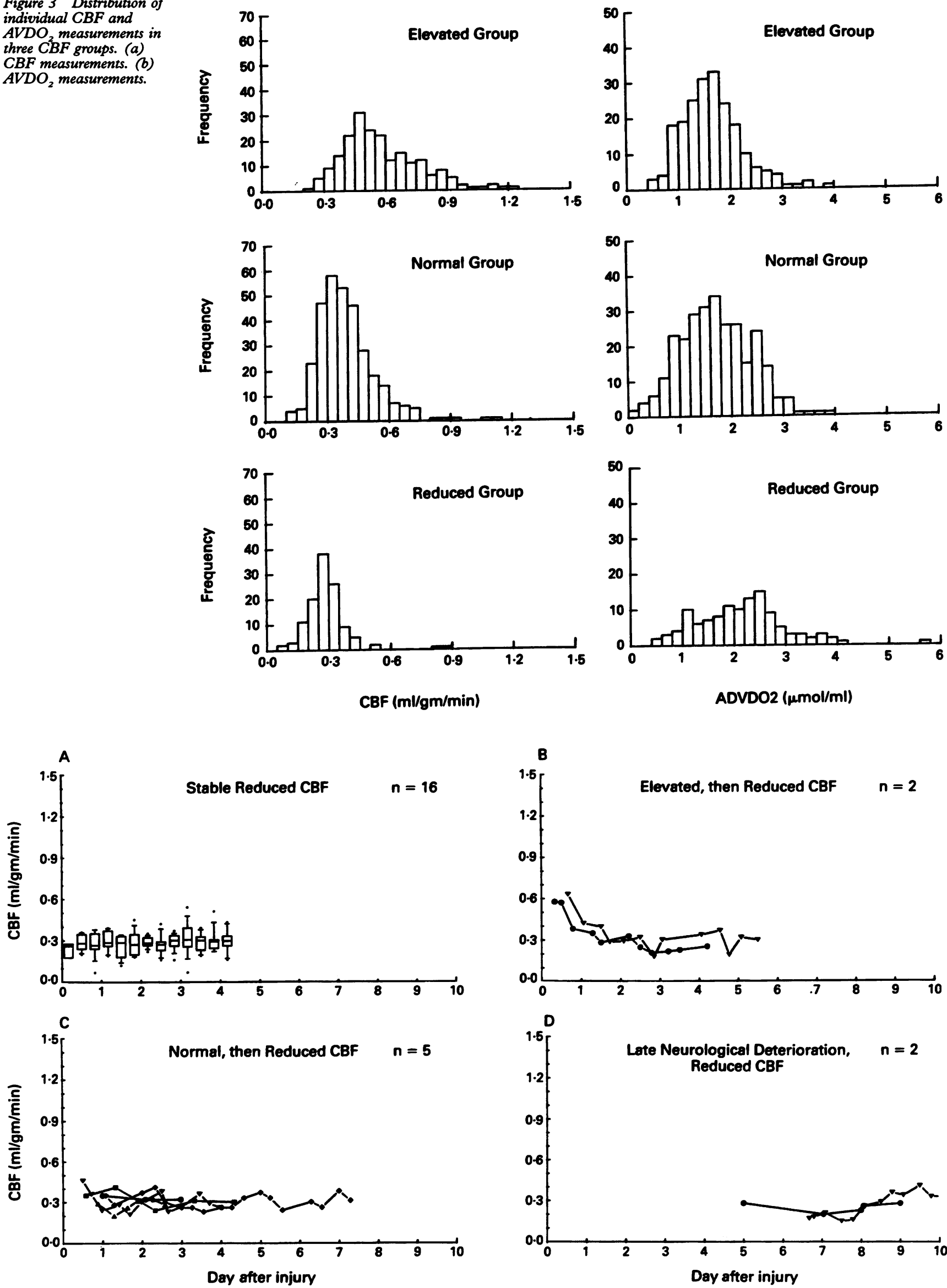

Figure 4 Patterns of evolution of $C B F$ observed on serial measurements in patients with reduced CBF Horizontal line across box depicts median CBF for 8 hour period; top and bottom of box represent 75th and 25th percentiles respectively; error bars mark 90th and 10th percentiles. Outlying points are shown as filled circles. (a) Stable reduced CBF pattern observed in 16 of 25 patients with reduced CBF. (b) Pattern of initially elevated, then reduced $C B F$ observed in 2 patients. (c) Pattern of initially normal, then reduced CBF observed in 5 patients. (d) Pattern of CBF in two patients who were not comatose on admission to hospital but who later deteriorated to coma. Reduced CBF values were obtained on the fifth and sixth days after injury when they neurologically deteriorated. 


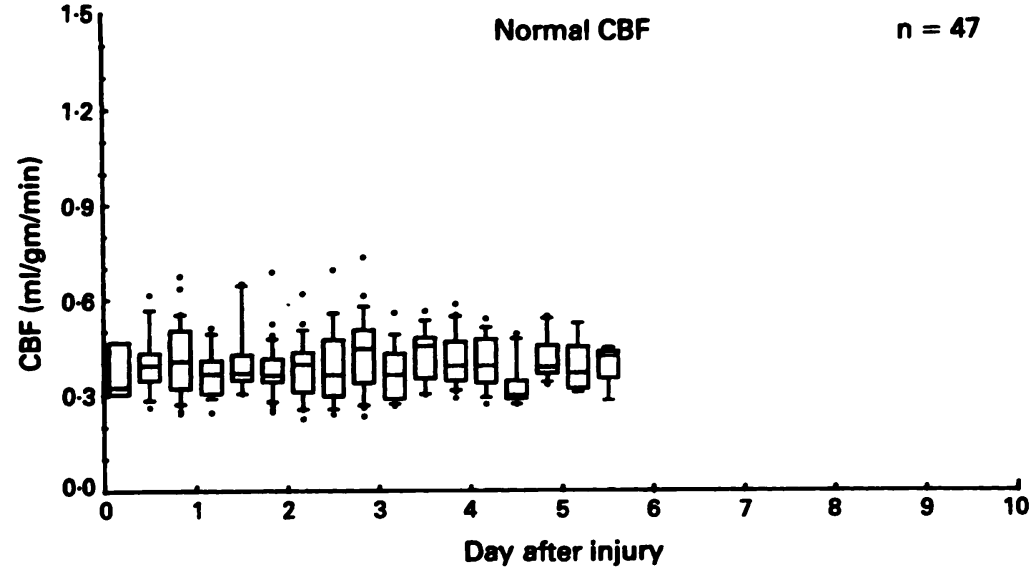

Figure 5 Serial measurements of $C B F$ in 47 patients with normal CBF. Horizontal line across box depicts median CBF for 8 hour period; top and bottom of box represent 75th and 25th percentiles respectively; error bars mark 90 th and 10th percentiles. Outlying points are shown as filled circles.

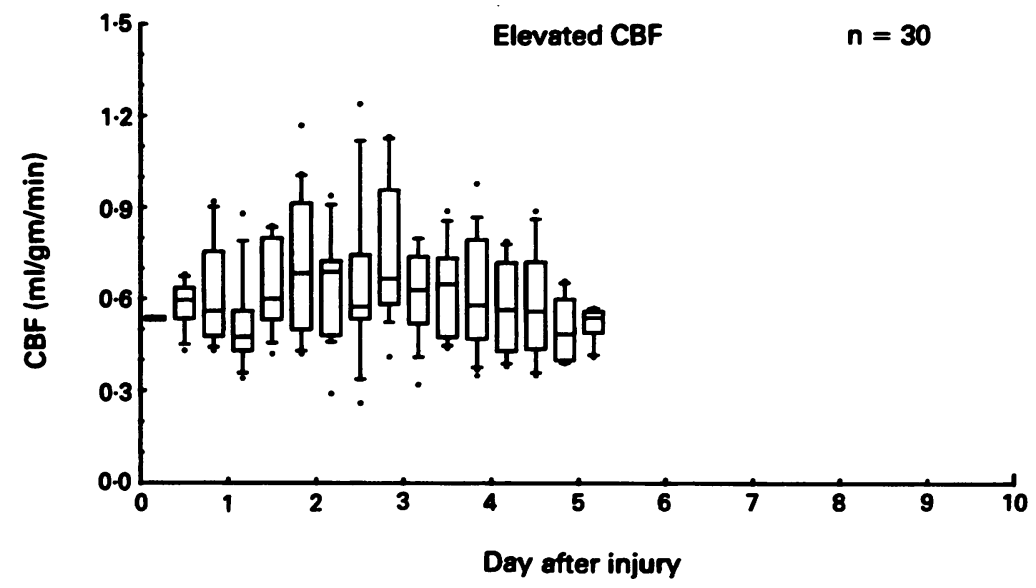

Figure 6 Serial measurements of $C B F$ in 30 patients with a raised CBF. Horizontal line across box depicts median CBF for 8 hour period; top and bottom of box represent 75th and 25th percentiles respectively; error bars mark 90th and 10th percentiles.

Outlying points are shown as filled circles.

raised CBF (fig 6) was present on the initial measurements of CBF (15 patients) or developed within the first 24-48 hours (15 patients). Four patients with raised CBF who developed intracranial hypertension refractory to treatment with hyperventilation, mannitol, and CSF drainage and who were treated with barbiturates all had raised CBF soon after injury, which persisted for many days. Other patients, however, had raised CBF without great intracranial hypertension. The hyperaemia tended to be more transient in the patients with normal ICP.

Relation of cerebral blood flow to neurological outcome

In the patients with a reduced CBF the mortality was $32 \%$ at three months after injury, compared with $21 \%$ in patients with a normal $\mathrm{CBF}$ and $20 \%$ in patients with a raised elevated CBF (fig 7). The patients with a reduced CBF were more likely to have an outcome of severe disability or persistent vegetative state $(48 \% v 39 \%$ of patients with a normal CBF and $27 \%$ of patients with raised CBF). Twenty per cent of patients with a reduced CBF had a good recovery or moderate disability at three months after injury compared with $53 \%$ of patients with a raised CBF and $41 \%$ of patients with a normal CBF.

Association of cerebral blood flow with demographic and systemic factors

The ages of the patients ranged from 17 to 72 years. CBF was found to be related to age. The age of the patients was highest in the group with reduced CBF, averaging 39 (13) years, compared with 34 (14) years in the group with normal CBF and 33 (15) years in the group with raised $\mathrm{CBF}$.

CBF was not related to the type of injury or to the initial Glasgow Coma Score. Patients with penetrating head injuries were evenly distributed among the three groups. The incidence of intracranial haematoma was not significantly different in the three groups $(52 \%$ in the reduced CBF group $v 62 \%$ in the normal group and $60 \%$ in the group with raised $\mathrm{CBF}$ ). The distribution of Glasgow Coma Scores ( $57 \%$ GCS $\leq 6,43 \%$ GCS $>6$ ) was not different in the three groups.

$\mathrm{CMRO}_{2}$ was significantly lower in the patients with reduced $\mathrm{CBF}$, averaging 0.62 $(0.20) \mu \mathrm{mol} / \mathrm{g} / \mathrm{ml}$, compared with $0.76(0.21)$ $\mu \mathrm{mol} / \mathrm{g} / \mathrm{min}$ in patients with normal CBF and $0.98(0.22) \mu \mathrm{mol} / \mathrm{g} / \mathrm{min}$ in patients with raised CBF.

Mean ICP and the highest ICP recorded during the period of ICP monitoring were in the same range in all three groups of patients (table 3). Since an ICP $>20 \mathrm{~mm} \mathrm{Hg}$ was vigorously treated, treatment might have masked differences in the severity of intracranial hypertension. The ICP treatment score was used to estimate the severity of intracranial hypertension. Both the mean score and the highest score were slightly lower in the group with reduced $C B F$, although the differences were not significant.

Systemic factors that might alter CBF, including blood pressure, arterial $\mathrm{PCO}_{2}$ tem-

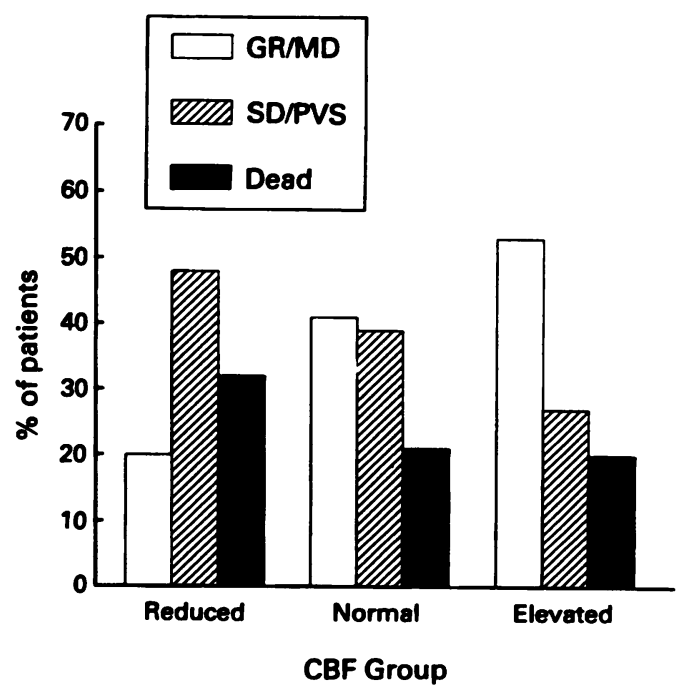

Figure 7 Relation of $C B F$ to neurological outcome. Horizontal line across box depicts median CBF for 8 hour period; top and bottom of box represent 75th and 25th percentiles respectively; error bars mark 90th and 10th percentiles. Outlying points are shown as filled circles. 
perature, and haemoglobin concentration were related to CBF measurements. Systemic factors that were responsible for transient reductions in CBF included pronounced hypocapnia in six patients and hypotension in one patient. Barbiturate administration for refactory intracranial hypertension reduced CBF in 5 of 9 patients. Systemic factors that were responsible for transient increases in CBF included hypoxia in one patient and hypercapnia in five patients.

Because of the reversible nature of the reduction in CBF in the seven patients with hypocapnia or hypotension, these patients were not included in the group with reduced CBF unless their $C B F$ remained reduced after treatment. In the nine patients who were given barbiturates for refractory intracranial hypertension, the CBF before barbiturates were given was used to classify the patient. The six patients with transient increase in CBF due to hypoxia or hypercapnia were not included in the group with raised CBF unless the CBF remained raised after correction of the blood gas abnormality. No significant differences in these systemic factors were found among the three groups (table 3).

Hypocapnia and hypotension did not seem to be important contributing factors to the abnormal CBF in the group with reduced CBF. In fact, the trend was for the patients in this group to have a higher $\mathrm{PCO}_{2}$ and cerebral perfusion pressure (CPP) than in the other two groups.

Anaemia, hypertension, and fever did not seem to be major contributing factors to the abnormal CBF in the group with raised CBF. CPP tended to be lower in the groups with raised and normal CBF, suggesting that hypertension was not the cause of the increased CBF. Body temperature tended to be slightly higher and mean haemoglobin concentration slightly lower in the group with raised CBF than in the groups with normal or reduced CBF. Although the differences were not significant, a small contribution by the factors of anaemia and fever cannot be ruled out.

\section{Logistic regression model}

To determine whether the difference in neurological outcome among the three groups reflected the effect of other covariates, logistic regression analysis was used as described above. The final model is shown in table 4 . When the effect of CBF on neurological outcome was adjusted for age, initial Glasgow Coma Score, haemoglobin concentration, cerebral perfusion pressure, and cerebral oxygen consumption a reduced CBF was still significantly associated with an unfavourable neurological outcome.

Neurological outcome tended to be better in younger patients, but an age difference did not completely account for the unfavourable outcome of the group with reduced CBF. The logistic regression model results indicated that for a patient 30 years old with a $\mathrm{CMRO}_{2}$ of $0.9 \mu \mathrm{mol} / \mathrm{g} / \mathrm{min}$ and a Glasgow Coma Score $\leq 6$ the probability of a favourable outcome was 0.16 with a reduced $C B F, 0.29$ with a normal $\mathrm{CBF}$, and 0.55 with a raised $\mathrm{CBF}$ (fig 8).

When the entire group of patients was considered, $\mathrm{AVDO}_{2}$ reflected the level of the CBF (fig 2), and a high $\mathrm{AVDO}_{2}$ tended to be associated with an unfavourable outcome. However, within each CBF group a higher $\mathrm{AVDO}_{2}$ was associated with a better outcome. The most likely explanation for this apparent paradox is that for any given $\mathrm{CBF}$, a higher $\mathrm{AVDO}_{2}$ indicates a higher $\mathrm{CMRO}_{2}$. As shown in figure 9, within each CBF group a higher $\mathrm{CMRO}_{2}$ was associated with a better outcome. It is important to emphasise, however, that the

Table 3 Relation of demographic and physiological variables to cerebral blood flow and to neurological outcome. Values are means (SDs) unless otherwise stated

\begin{tabular}{|c|c|c|c|c|c|}
\hline & \multicolumn{3}{|c|}{ Cerebral blood flow } & \multirow{2}{*}{$\begin{array}{l}\text { Relation } \\
\text { to } C B F \\
p \text { value }\end{array}$} & \multirow{2}{*}{$\begin{array}{l}\text { Relation } \\
\text { to outcome } \\
\text { p value }\end{array}$} \\
\hline & Reduced & Normal & Raised & & \\
\hline $\begin{array}{l}\text { No of patients } \\
\text { Age (years) }\end{array}$ & $\begin{array}{l}25 \\
39 \text { (13) }\end{array}$ & $\begin{array}{l}47 \\
34(14)\end{array}$ & $\begin{array}{l}30 \\
33(15)\end{array}$ & 0.01 & 0.07 \\
\hline \\
\hline $\begin{array}{l}\% \text { With Glasgow coma score } \\
\leq 6\end{array}$ & 56 & 57 & 49 & 0.99 & 0.01 \\
\hline $\begin{array}{l}\text { \% Pupils abnormal } \\
\text { CMRO }_{2} \\
\text { CMRL }^{\text {MMR }}\end{array}$ & $\begin{array}{l}18 \\
0.62(0.20) \\
-0.01(0.02)\end{array}$ & $\begin{array}{l}18 \\
0.76(0.21) \\
-0.02(0.03)\end{array}$ & $\begin{array}{l}13 \\
0.98(0.22) \\
-0.02(0.05)\end{array}$ & $\begin{array}{l}0.76 \\
0.01 \\
0.65\end{array}$ & $\begin{array}{l}0.03 \\
0.04 \\
0.79\end{array}$ \\
\hline \multicolumn{6}{|c|}{ Type of injury: } \\
\hline $\begin{array}{l}\text { \% with penetrating injury } \\
\text { Severity of intracranial hyper- } \\
\text { tension: }\end{array}$ & 8 & 11 & 10 & 0.94 & $0 \cdot 17$ \\
\hline ICP & $15(5)$ & $14(5)$ & $14(15)$ & 0.75 & 0.97 \\
\hline Highest ICP & $30(12)$ & 31 (14) & 30 (15) & 0.99 & 0.92 \\
\hline ICP treatment score & $4(2)$ & $5(3)$ & $5(3)$ & $0 \cdot 28$ & 0.96 \\
\hline Highest ICP treatment score & $6(3)$ & 7 (4) & $7(4)$ & 0.38 & 0.72 \\
\hline \multicolumn{6}{|l|}{ Systemic factors: } \\
\hline CPP & $89(13)$ & $82(12)$ & $85(14)$ & 0.08 & $0 \cdot 10$ \\
\hline Highest CPP & $118(21)$ & $103(17)$ & $110(16)$ & 0.01 & $0 \cdot 17$ \\
\hline Lowest CPP & $63(18)$ & $63(18)$ & $62(16)$ & 0.99 & $0 \cdot 88$ \\
\hline $\mathrm{PCO}_{2}$ & $33(4)$ & $30(5)$ & $32(5)$ & 0.04 & 0.54 \\
\hline Lowest $\mathrm{PCO}_{2}$ & $26(4)$ & $26(4)$ & $26(5)$ & 0.74 & $0 \cdot 26$ \\
\hline Temperature & $99 \cdot 4(1 \cdot 3)$ & $99 \cdot 3(1 \cdot 4)$ & $99 \cdot 7(1 \cdot 1)$ & 0.42 & 0.66 \\
\hline $\begin{array}{l}\text { Haemoglobin } \\
\text { Lowest haemoglobin }\end{array}$ & $9.5(1.2)$ & $\begin{array}{r}10 \cdot 7(1.0) \\
9.6(1.3)\end{array}$ & $\begin{array}{r}10.5(1.3) \\
9 \cdot 2(1.5)\end{array}$ & $\begin{array}{l}0.43 \\
0.43\end{array}$ & 0.36 \\
\hline
\end{tabular}

$\mathrm{CBF}=$ cerebral blood flow $(\mathrm{ml} / \mathrm{g} / \mathrm{min}) ; \mathrm{CMRO}_{2}=$ cerebral metabolic rate of oxygen $(\mu \mathrm{mol} / \mathrm{g} / \mathrm{min}) ; \mathrm{CMRL}=$ cerebral metabolic rate of lactate $(\mu \mathrm{mol} / \mathrm{g} / \mathrm{min}) ; \mathrm{ICP}=$ intracranial pressure $(\mathrm{mm} \mathrm{Hg}) ; \mathrm{CPP}=$ cerebral perfusion pressure $(\mathrm{mm} \mathrm{Hg})$. 
Table 4 Logistic regression model of the relation of cerebral blood flow to neurological outcome. Dependent variable was favourable outcome (Glasgow Outcome Score at three months $=$ good recovery/moderate disability)

\begin{tabular}{lcll}
\hline Predictor & Coefficient & $\chi^{*}$ & p Value \\
\hline CBF pattern: & & & 0.04 \\
$\quad$ Raised & 1.00 & 6.15 & \\
Normal & -0.12 & 0.13 & \\
$\quad$ Reduced & -0.88 & 3.94 & \\
Age (per year) & -0.03 & 1.81 & 0.18 \\
GCS category: & & & 0.02 \\
3-6 & -0.60 & 5.86 & \\
>6 & 0.60 & 5.86 & \\
CMRO & 3.44 & 6.87 & 0.01 \\
CPP & -0.04 & 3.68 & 0.06 \\
Haemoglobin & -0.65 & 6.38 & 0.01 \\
Intercept & 8.32 & 5.40 & 0.02 \\
\hline
\end{tabular}

$\mathrm{CBF}=$ cerebral blood flow; $\mathrm{GCS}=$ Glasgow coma score $\mathrm{CMRO}_{2}=$ cerebral metabolic rate of oxygen; CPP = cerebra perfusion pressure.

$\chi^{2}$ test for individual coefficient.

* $\mathrm{p}$ Value for complete variable.

Figure 8 Effects of age and $C B F$ on neurological outcome. Curves were obtained from coefficients of logistic regression model for a typical patient with a $G C S \leq 6$ and $C M R O$ of $9 \mu \mathrm{mol} / \mathrm{g} / \mathrm{min}$. Probability of a favourable outcome tended to decrease with advancing age, but for a given age the probability of a favourable outcome was significantly lower in patients with a reduced $C B F$ :

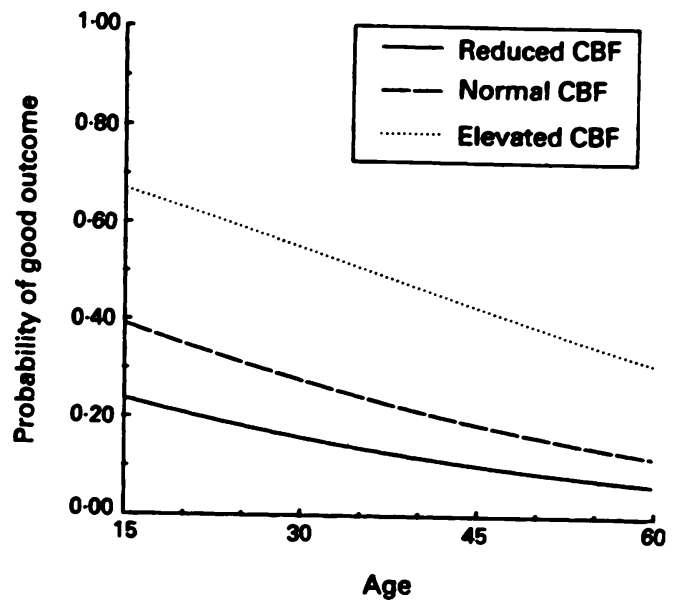

Figure 9 Effects of $C B F$ and $\mathrm{CMRO}_{2}$ on neurological outcome. Curves were obtained from logistic regression model for a typical patient of age 30 years with a $G C S \leq 6$. Probability of a favourable outcome varied with $\mathrm{CMRO}_{2}$; for any given $\mathrm{CMRO}_{2}$ the probability of a favourable outcome was significantly lower in patients with a reduced $C B F$. reduced, 0.29 if the CBF was normal, and 0.55 if the CBF was raised.

\section{Discussion}

A reduced cerebral blood flow could directly contribute to a poor neurological outcome if the resulting availability of cerebral oxygen were inadequate to support the brain's metabolic requirements. Cerebral blood flow can be decreased by a number of pathophysiological processes after head injury, including intracranial hypertension, cerebral vasospasm, and the occlusion, compression, or injury of intracranial vessels. Systemic factors such as hypocapnia or hypotension can reduce cerebral blood flow. In addition, when the oxygen carrying capacity of blood is low, owing to anaemia or hypoxia, even a normal cerebral blood flow may be inadequate. The present study shows a significant correlation between a reduced CBF and a poor outcome.

\section{Limitations of the present study}

The nitrous oxide saturation method accurately measures global CBF. The serial nature of the CBF measurements permitted by the nitrous oxide method is a unique feature of the present study. However, regional abnormalities of CBF can exist in the presence of a normal global CBF. This limitation would be of greater concern had the studies shown no relation between $\mathrm{CBF}$ and outcome.

To study the relation of CBF and neurological outcome the patients were categorised as having a reduced, normal, or raised CBF on the basis of their deviation from the normal values for CBF. The CBF values were compared to normal values to have a standard for comparison, and not because it was thought that the normal range was appropriate for a comatose patient. The CBF values were compared to the normal range adjusted for $\mathrm{PCO}_{2}$ since the patients varied considerably in the level of the $\mathrm{PCO}_{2}$. The $\mathrm{CO}_{2}$ reactivity of each patient was not known but could have been impaired in severely injured patients.

Although all the serial CBF values of most patients fell into one category, some patients had values that ranged across two or three categories. There were too few of these patients with a CBF that evolved over time for a separate analysis. Patients who had a reduced $\mathrm{CBF}$ for at least 16 hours were included in the group with reduced CBF even though they may have had periods during which the flow was normal or even raised. These patients comprised only $7 \%$ of the total group and their presence did not alter the mean values of CBF for the three groups, but the results might have been different if other conventions had been followed in classifying the patients.

Ten patients with penetrating head injuries were included in the patients studied, although most other studies of CBF after head injury have limited their analysis to patients with closed head injuries. The penetrating head injuries were evenly distributed among the three groups of patients. The result of a logistic regression analysis for the patients with closed 
head injury was unchanged by adding the data from the penetrating injuries.

Determinants of neurological outcome: comparison to previous studies

Age is an important determinant of neurological outcome after a severe head injury. ${ }^{18-21}$ Except for the very young, the lower the age, the better the neurological recovery after a severe head injury. Age is also a factor in the CBF response to injury. Most studies have found that a raised CBF is more common in children and adolescents than in adults. Langfitt $e t$ al described two adolescents with a raised CBF on initial evaluation, but adult patients typically had a reduced $\mathrm{CBF}^{7}$ Bruce et al found that $\mathrm{CBF}$ was raised in six children with diffuse swelling on CT scan. ${ }^{22}$ Obrist et al reported the incidence of normal or raised CBF to be $46 \%$ in head injured patients over 20 years of age and $70 \%$ in patients aged 15-20 years. ${ }^{11}$ Muizelaar et al found normal or raised CBF values in $88 \%$ of children with acute head injury. ${ }^{12}$

The severity of the neurological injury, quantitated by the initial Glasgow Coma Score or by the degree of suppression of $\mathrm{CMRO}_{2}$, is an important determinant of survival and of neurological recovery in head injured patients. ${ }^{1323-25}$ While the Glasgow Coma Score of patients with a head injury has been associated with the $\mathrm{CMRO}_{2}{ }^{11} \mathrm{CBF}$ has been found to have an inconsistent relation in all but a few studies. Muizelaar found a significant relation between motor score and CBF in the contralateral hemisphere measured within the first 24 hours after injury. After 24 hours there was no relation between Glasgow Coma Score and $\mathrm{CBF}^{26}$ Obrist et al found a significant relation between neurological status and CBF, but only in patients who did not develop hyperaemia. $^{8}$ Most other CBF studies have failed to show any association between CBF and neurological status.

Severity of intracranial hypertension has been associated with neurological outcome. ${ }^{202127}$ Miller et al found that in patients with mass lesions only a very high ICP $(>40 \mathrm{~mm} \mathrm{Hg}$ ) was associated with a poor outcome, while in patients with a diffuse brain injury any increase in the ICP above $10 \mathrm{~mm} \mathrm{Hg}$ was associated with a poorer neurological outcome. ${ }^{20}$ The relation of intracranial hypertension and CBF, however, is controversial. Fieschi et al found a direct linear relation between resting CBF and ICP. ${ }^{3}$ Bruce et al reported the association of severe intracranial hypertension in children with CT scans showing diffuse swelling and greatly raised CBF values. ${ }^{2228}$ Obrist et al observed a similar association between raised CBF and intracranial hypertension in adults. ${ }^{11}$ Other studies have found either an inverse relation between CBF and ICP ${ }^{5}$ or no relation. ${ }^{4612}$

The intracranial pathology produced by injury has been associated with neurological outcome in some studies. ${ }^{202123} \mathrm{~A}$ mortality of $23 \%$ has been reported in patients with diffuse injuries, compared with $40 \%$ in patients with haematomas. ${ }^{20}$ The poorer outcome in patients with haematomas may be partly due to the older age of the patients. When age was adjusted for, the presence of an intracranial haematoma increased the likelihood of a poor outcome only in patients who were less than 20 years old. ${ }^{23}$ Raised CBF has typically been associated with diffuse swelling. The presence of an intracranial haematoma might be expected to be associated with reduced CPP and $\mathrm{CBF}$; however, after evacuation of the haematoma $\mathrm{CBF}$ can be quite variable.

The present study suggests that in addition to these factors of age, neurological status, and raised ICP the level of CBF may be a factor in determining neurological outcome. The cause of the poorer outcome in the patients with reduced CBF is not clear. The association could not be explained on the basis of any identifiable confounding factor. The mean CBF for the group with reduced CBF was 0.29 $(0.05) \mathrm{ml} / \mathrm{g} / \mathrm{min}$, which is well above ischaemic thresholds for the brain. ${ }^{29}$ These ischaemic thresholds were determined in normal experimental animals, and it may not be appropriate to extrapolate these data directly to patients with a neurological injury. It might be hypothesised that a low CBF does not allow for adequate compensation during periods of stress. Transient periods of hypoxia, hypotension, or intracranial hypertension might be more likely to result in ischaemia in patients with reduced $\mathrm{CBF}$ reserve, adversely affecting outcome.

This study was supported by United States Public Health Service Grant NS27616. The authors gratefully acknowledge the patient care given by the NICU nurses at Ben Taub General Hospital and the technical assistance of Drs Rajesh Pahwa, Jonathan Raju, Benjamin Kuo, and Pedro Caram Jr.

1 Tabaddor K, Bhushan C, Pevsher PH, et al. Prognostic value of cerebral blood flow (CBF) and cerebral metabolic rate of oxygen $\left(\mathrm{CMRO}_{2}\right)$ in acute head trauma. $f$ Trauma 1972;12:1053-5.

2 Bruce DA, Langfitt TW, Miller JD, et al. Regional cerebral blood flow, intracranial pressure, and brain metabolism in comatose patients. $\mathcal{F}$ Neurosurg 1973;38:131-44.

3 Fieschi C, Battistini N, Beduschi A, et al. Regional cerebral blood flow and intraventricular pressure in acute head injuries. I Neurol Neurosurg Psychiatry 1974;37:1378-88.

4 Overgaard J, Tweed WA. Cerebral circulation after head injury. Part 1 . Cerebral blood flow and its regulation after injury. Part 1 . Cerebral blood flow and its regulation after
closed head injury with emphasis on clinical correlation. $\mathcal{f}$ Neurosurg 1974;41:531-41.

5 Gobiet W, Grote W, Bock WJ. The relationship between intracranial pressure, mean arterial pressure and cerebral blood flow in patients with severe head injury. Acto Neurochir (Wien) 1975;32:13-24.

6 Enevoldsen EM, Cold G, Jensen FT, et al. Dynamic changes in regional CBF, intraventricular pressure, $\mathrm{CSF} \mathrm{pH}$ and lactate levels during the acute phase of head injury. $f$ Neurosurg 1976;44:191-214.

7 Langfitt TW, Obrist WD, Gennarelli TA, et al. Correlation of cerebral blood flow with outcome in head-injured patients. Ann Surg 1977;186:411-4.

8 Obrist WD, Gennarelli TA, Segawa $\mathrm{H}$, et al. Relation of cerebral blood flow to neurological status and outcome in head-injured patients. $\mathcal{F}$ Neurosurg 1979;51:292-300.

9 Overgaard J, Molsdal C, Tweed WA. Cerebral circulation after head injury. Part 3. Does reduced regional cerebral blood flow determine recovery of brain function after blood flow determine recovery of brain function
blunt head injury? $\mathcal{Y}$ Neurosurg 1981;55:63-74.

10 Overgaard J, Tweed WA. Cerebral circulation after head injury. Part 4. Functional anatomy and boundary-zone injury. Part 4. Functional anatomy and boundary-zone Neurosurg 1983;59:439-46.

11 Obrist WD, Langfitt TW, Jaggi JL, et al. Cerebral blood flow and metabolism in comatose patients with acute head injury: relationship to intracranial hypertension. $f \mathrm{Neu}$ rosurg 1984;61:241-53.

12 Muizelaar JP, Marmarou A, DeSalles AAF, et al. Cerebral blood flow and metabolism in severely head-injured children. Part 1. Relationship with GCS score, outcome, ICP, and PVI. of Neurosurg 1989;71:63-71.

13 Jaggi JL, Obrist WD, Gennarelli TA, Langfitt TW. Relationship of early cerebral blood flow and metabolism to outcome in acute head injury. $f$ Neurosurg 1990 72:176-82. 
14 Robertson CS, Grossman RG, Goodman JC, et al. The predictive value of cerebral anaerobic metabolism with cerebral infarction after head injury. $\mathcal{F}$ Neurosurg 1987 67:361-8.

15 Robertson CS, Narayan RK, Gokaslan ZL, et al. Cerebral $\mathrm{AVDO}_{2}$ as an estimate of cerebral blood flow in comatose patients. I Neurosurg 1989;70:222-30.

16 Kety SS, Schmidt CF. The nitrous oxide method for the quantitative determination of cerebral blood flow in man: quantitative determination of cerebral blood flow in man: theory, procedure,

17 Cox DR. Analysis of binary data. London: Methuen, 1970.

18 Luerssen TG, Klauber MR, Marshall LF. Outcome from head injury related to patient's age. A longitudinal study of adult and pediatric head injury. $f$ Neurosurg 1988 68:409-12.

19 Teasdale G, Skene A, Parker L, et al. Age and outcome of severe head injury. Acta Neurochir 1979; suppl 28: $140-3$

20 Miller JD, Becker DP, Ward JD, et al. Significance of W rosurg 1977;47:501-16.

21 Alberico AM, Ward JD, Choi SC, et al. Outcome after severe head injury: relationship to mass lesions, diffuse injury, and ICP course in pediatric and adult patients. $f$ Neurosurg 1987;67:648-56.

22 Bruce DA, Raphaely RC, Goldberg AI, et al. Pathophysiol- ogy, treatment, and outcome following severe head injury in children. Child's Brain 1979;5:174-91.

23 Jennett B, Teasdale G, Braakman R, et al Prognosis in series of patients with severe head injury. Neurosurgery $1977 ; 4: 283$

24 Jennett B, Teasdale G, Braakman $R$, et al. Predicting outcome in individual patients after severe head injury. Lancet 1979; i: 1031-4.

25 Narayan RK, Greenberg RP, Miller JD, et al. Improved confidence of outcome prediction in severe head injury: A comparative analysis of the clinical examination, multimodality evoked potentials, CT scanning and intracranial modality evoked potentials, CT scannin

pressure. F Neurosurg 1981;54:751-62.
26 Muizelaar JP. Cerebral blood flow, cerebral blood volume, and cerebral metabolism after severe head injury. In: Becker DP, Gudeman SK, eds. Textbook of head injury. Philadelphia: Saunders, 1989:221-40.

27 Fleischer AS, Nettleton SP, Tindall GT. Continuous monitoring of intracranial pressure in severe closed head injury without mass lesions. Surg Neurol 1976;6:31-4.

28 Bruce DA, Alavi A, Bilaniuk $K$, et al. Diffuse cerebral swelling following head injuries in children: the syndrome of "malignant brain edema" 7 Neurosurg 1981:54: 170-8.

29 Jones TH, Morawetz RB, Crowell RM, et al. Threshold of focal ischemia in awake monkeys. $f$ Neurosurg 1981; 54:774-82. 